\title{
Influence of the binder types on the electrochemical characteristics of natural graphite electrode in room-temperature ionic liquid
}

\author{
Koichi UI ${ }^{\mathrm{a} *}$, Jun TOWADA ${ }^{\text {a }}$, Sho AGATSUMA ${ }^{\text {a }}$, Naoaki KUMAGAI ${ }^{\text {a }}$, \\ Keigo YAMAMOTO $^{\mathrm{b}}$, Hiroshi HARUYAMA ${ }^{\mathrm{b}}$, Ken TAKEUCHI ${ }^{\mathrm{c}}$, \\ and Nobuyuki KOURA ${ }^{\mathrm{b}}$
}

${ }^{a}$ Department of Frontier Materials and Functional Engineering, Graduate School of Engineering, Iwate University, Morioka, Iwate 020-8551, Japan.

${ }^{b}$ Faculty of Science and Technology, Tokyo University of Science, Noda, Chiba 278-8510, Japan

${ }^{c}$ Faculty of Industrial Science and Technology, Tokyo University of Science, Tomino, Oshamanbe, 049-3514, Japan

- Article type

- *Corresponding author

- Business Affiliation

- Full postal address

- Phone and fax number

- E-mail address

\section{Full Length Article}

Associate Professor Koichi UI (M)

Iwate University

4-3-5 Ueda, Morioka, Iwate 020-8551, Japan

$+81-19-621-6340 / 6314$

kui@iwate-u.ac.jp 


\section{Graphical abstract:}

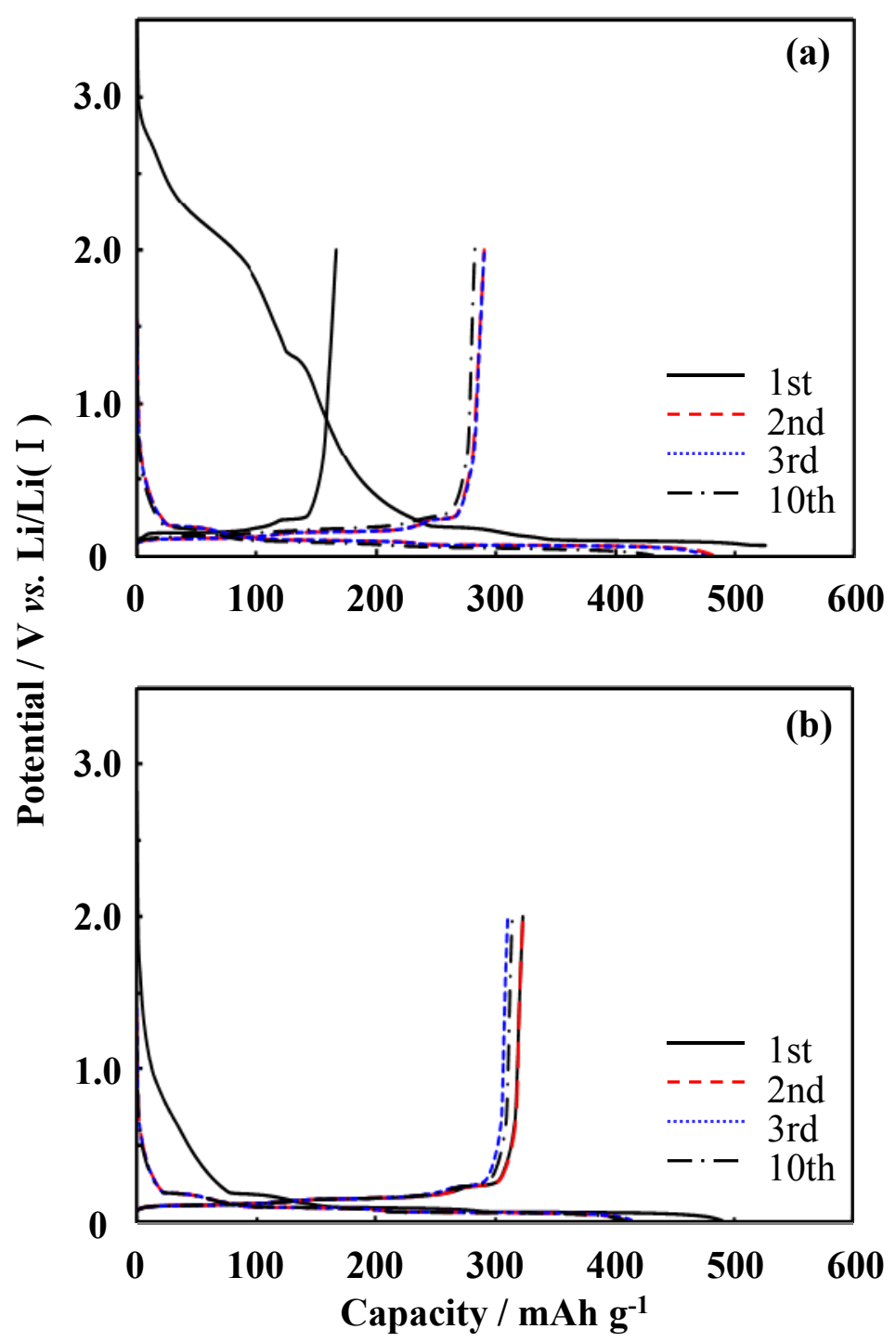

\section{Highlights}

- The cycling curves of the NG-3 electrode using the PVdF binder are shown in Fig.(a).

- The cycling curves of the NG-3 electrode using the PAA binder are shown in Fig.(b).

- The use of the PAA binder improved the initial cycling efficiency of it.

- The use of the PAA binder repressed the reduction reaction of $\mathrm{SOCl}_{2}$. 


\begin{abstract}
To improve the electrochemical characteristics of the natural graphite (NG-3) negative electrode in the $\mathrm{LiCl}$ saturated $\mathrm{AlCl}_{3}$-1-ethyl-3-methylimizadolium chloride + thionyl chloride $\left(\mathrm{SOCl}_{2}\right)$ melt as the electrolyte for non-flammable lithium-ion batteries, we examined the influence of the binder types on its electrochemical characteristics. The cyclic voltammograms showed that the reduction current at $1.2-3.2 \mathrm{~V}$ vs. $\mathrm{Li} / \mathrm{Li}(\mathrm{I})$ was repressed using polyacrylic acid (PAA) as the binder. The charge-discharge tests showed that the discharge capacity and the charge-discharge efficiency of the NG-3 electrode coated with the PAA binder at the 1 st cycle were $322.8 \mathrm{mAh} \mathrm{g}^{-1}$ and $65.6 \%$, respectively. Compared with the NG-3 electrode using the conventional poly (vinylidene fluoride) binder, it showed considerably a better cyclability with the discharge capacity of $302.1 \mathrm{mAh} \mathrm{g}^{-1}$ at the 50th cycle. $\mathrm{Li}(\mathrm{I})$ ion intercalation into the graphite layers could be improved because the NG-3 electrode coated with the PAA binder changed to a golden-yellow color after the 1st charging, and the formation of first stage $\mathrm{LiC}_{6}$ was demonstrated by X-ray diffraction (XRD) measurement. In addition, the XRD and X-ray photoelectron spectroscopy indicated that one of the side reactions during charging was the formation of $\mathrm{LiCl}$ on the graphite surface regardless of the binder types.
\end{abstract}

Keywords: graphite, negative electrode, lithium-ion battery, ionic liquid, polyacrylic acid, binder 


\section{Introduction}

In recent years, an attempt has been made to use lithium-ion secondary batteries as automotive power supplies and as an electric energy storage system for grid-connection with new energy resources, but an enhancement of the energy density is still necessary. Further improvement of its safety is also necessary because there have been ignition accidents of lithium-ion secondary batteries. Therefore, novel electrolytes and electrode materials are being widely developed. Especially, room-temperature ionic liquids (RTILs) as novel electrolytes have recently been investigated because they have the advantages of a low volatility and non-flammability.

However, the charge-discharge characteristics of a graphite negative electrode in many types of RTILs are poor. This would be due to the electrochemical organic cation intercalation into the graphite layers $[1,2]$ before the formation of a solid electrolyte interface (SEI) film on the graphite particles during the 1st charging. Recently, it has been reported that the graphite electrode indicated good charge-discharge characteristics by adding an additive such as vinylene carbonate [3] to the RTILs or using the RTILs such as $N, N$-diethyl- $N$-methyl- $N$-(2-methoxyethyl) ammonium bis(trifluoromethylsulfonyl) amide (DEME-TFSA) [4], 1-ethyl-3-methylimizadolium bis(fluorosulfonyl) amide (EMI-FSA) [5], and $N$-methyl- $N$-propylpyrrolidinium bis(fluorosulfonyl) amide ( $\left.\mathrm{P}_{13}-\mathrm{FSA}\right)$ [6].

On the other hand, our group found that polyacrylic acid (PAA), which is a water-soluble polymer, was able to be used as the binder of the graphite electrode [7]. In a propylene carbonate (PC)-based electrolyte, electrochemical $\mathrm{Li}^{+}$ion intercalation into graphite layers does not occur due to the co-intercalation and significantly reductive decomposition of PC molecules at around $1.0 \mathrm{~V}$ vs. $\mathrm{Li} / \mathrm{Li}^{+}$, causing exfoliation of the graphite layers [8]. It is 
expected that the charge-discharge reaction of the graphite electrode would be improved in RTILs because the uses of PC-based electrolyte and PAA binder enabled the reaction [7]. We have investigated the property of the electrolyte consisting of the $\mathrm{AlCl}_{3}$-1-ethyl-3-methyl imidazolium chloride (EMIC) melt, because the $60.0 \mathrm{~mol} \%$ $\mathrm{AlCl}_{3}-40.0 \mathrm{~mol} \% \mathrm{EMIC}^{-\mathrm{LiCl}_{\text {sat. }}}+0.1 \mathrm{~mol} \mathrm{dm}^{-3}$ thionyl chloride $\left(\mathrm{SOCl}_{2}\right)$ melt exhibiting relatively good physical properties such as a low viscosity $\left(23.4 \mathrm{mPa} \mathrm{s}\right.$ at $\left.25^{\circ} \mathrm{C}\right)$ and high ionic conductivity $\left(11.5 \mathrm{mS} \mathrm{cm}^{-1}\right.$ at $\left.25^{\circ} \mathrm{C}\right)$ [9-12], and showed that the binder-free natural graphite electrode exhibited charge-discharge reaction in the melt $[13,14]$. The nearly reversible intercalation and deintercalation reactions of the $\operatorname{Li}(\mathrm{I})$ ions into and from the graphite layer were enabled by adding the small amount of $\mathrm{SOCl}_{2}$ to the melt although the initial cycling efficiency was not high.

In this study, we tried to improve the electrochemical characteristics of the natural graphite negative electrode in the $66.7 \mathrm{~mol} \% \mathrm{AlCl}_{3}-33.3 \mathrm{~mol} \% \mathrm{EMIC}^{-\mathrm{LiCl}_{\text {sat. }}}+0.1 \mathrm{~mol}$ $\mathrm{dm}^{-3} \mathrm{SOCl}_{2}$ melt. We will report the influence of the binder types on the graphite electrode using PAA as the binder, especially compared to the conventional poly (vinylidene fluoride) (PVdF) binder. The aims of this study are to understand the formation mechanism of surface film on graphite electrodes and then to prepare the graphite electrode showing the reversible $\mathrm{Li}(\mathrm{I})$ ion intercalation and deintercalation reaction in the RTILs.

\section{Experimental}

The natural graphite (Kansai Coke and Chemical Co. NG-3) electrodes coated with the PAA binder and PVdF binder were prepared in a similar way as previously reported [7]. In 
order to improve the dispersion state of the NG-3 particles and the electrochemical stability of the electrode, the graphite electrodes were prepared as follows. The suspension composed of 90 wt. \% NG-3 powder and 10 wt. \% binder was prepared using a disperse medium, and then stirred in a reagent bottle for $24 \mathrm{~h}$. The percentages by mass of the electrode material in the suspension for the PAA-NG-3 suspension (distilled water as disperse medium) and the PVdF-NG-3 suspension ( $N$-methylpyrrolidone as disperse medium) were 20.0 wt. $\%$ and 43.5 wt. $\%$, respectively. The suspension was coated on $\mathrm{Ni}$ mesh (Tokyo Screen Co., 100 mesh, $10 \mathrm{~mm} \times 10 \mathrm{~mm}$ ). It was then pressed for $10 \mathrm{~min}$ after air-drying at $80^{\circ} \mathrm{C}$ for $1 \mathrm{~h}$. Prior to their use, the PAA-NG-3 electrode and the PVdF-NG-3 electrode were dried in a vacuum at $200{ }^{\circ} \mathrm{C}$ and $180{ }^{\circ} \mathrm{C}$ for $3 \mathrm{~h}$, respectively.

The three-electrode cell, which consisted of the NG-3 electrode (W.E.) and a pressed lithium metal foil on the $\mathrm{Ni}$ mesh (R.E. and C.E.), was used for the electrochemical measurements. The $66.7 \mathrm{~mol} \% \mathrm{AlCl}_{3}-33.3 \mathrm{~mol} \%$ EMIC-LiCl $_{\text {sat. }}+0.1 \mathrm{~mol} \mathrm{dm}^{-3} \mathrm{SOCl}_{2}$ melt was prepared as previously reported $[14,15]$. The cells were assembled in a glove box (Miwa Mtg Co., Ltd., DBO-1NKP-1V-2) filled with dry argon at room temperature.

Cyclic voltammetry (CV) was performed using a computer-controlled electrochemical measuring system (Hokuto Denko, HZ-5000). The cyclic voltammograms were measured at the scan rate of $0.1 \mathrm{mV} \mathrm{s}^{-1}$ between the potentials of 0.0 and $2.0 \mathrm{~V}(v s . \mathrm{Li} / \mathrm{Li}(\mathrm{I})$ ). Hereafter all the potentials described are with regard to "vs. Li/ Li( I )" unless otherwise noted. The charge-discharge cycle tests were performed using an automatic battery charging-discharging instrument (Hokuto Denko, HJR-1010mSM8) at the current density of $175 \mathrm{~mA} \mathrm{~g}^{-1}\left(1 \mathrm{C}=350 \mathrm{~mA} \mathrm{~g}^{-1}\right)$ between $5 \mathrm{mV}$ and $2.0 \mathrm{~V}$. Especially, the charge condition 
was controlled using the relationship between the potential and the time: the charge process was stopped when the charge potential reached down to $5 \mathrm{mV}$ or the charge time reached to 3h. The crystal structure and surface analysis of the samples were examined by X-ray diffraction (XRD) using an X-ray diffractometer (Rigaku Denki, RINT2200) with Cu $\mathrm{K} \alpha$ radiation $(\lambda=0.15418 \mathrm{~nm})$ and tube voltage / tube current at $40 \mathrm{kV} / 30 \mathrm{~mA}$, and X-ray photoelectron spectroscopy (XPS) analysis (Perkin-Elmer, PHI 5600) with Al K $\alpha$ radiation $(\mathrm{h} v=1486 \mathrm{eV})$. The cells were disassembled in the glove box to obtain the electrode samples. The obtained samples were then washed with diethyl carbonate (Wako Chemical Industries, Ltd., superfire quality), and packaged in polypropylene film (Rigaku Denki, Cell sheet) to prevent any contact of the sample with air.

\section{Results and discussion}

The CVs were measured in order to investigate the electrochemical behavior of the NG-3 electrodes in the $66.7 \mathrm{~mol} \% \mathrm{AlCl}_{3}-33.3 \mathrm{~mol} \%$ EMIC-LiCl $_{\text {sat. }}+0.1 \mathrm{~mol} \mathrm{dm}{ }^{-3} \mathrm{SOCl}_{2}$ melt. Fig. 1(a) shows the CV of the NG-3 electrode using PVdF (10 wt.\%) as a conventional binder. The clear reduction current was observed around $2.8 \mathrm{~V}$ (vs. Li/ Li( I )), which might be due to the reduction of $\mathrm{SOCl}_{2}$ [16]. The small reduction current continuously appeared by scanning to a lower potential down to $0.2 \mathrm{~V}$. The reduction and oxidation currents corresponding to the intercalation and deintercalation reactions of the $\mathrm{Li}(\mathrm{I})$ ions into and from the graphite layer were observed in the potential range from 0.2 to $0.0 \mathrm{~V}$ and from 0.1 to $0.4 \mathrm{~V}$, respectively [17], indicating that the reversible charge-discharge reaction of the NG-3 electrode would occur in the melt. In contrast, Fig. 1(b) shows the CV of the NG-3 
electrode coated with PAA (10 wt.\%) as a binder. The reduction wave around $2.8 \mathrm{~V}$, which was observed in the PVdF binder (Fig. 1(a)), hardly appeared during the 1st cycle. The reduction wave at $3.0 \sim 0.2 \mathrm{~V}$ for the NG-3 electrode coated with the PAA binder was smaller than that for the NG-3 electrode using the PVdF binder. The redox peaks corresponding to the $\operatorname{Li}(\mathrm{I})$ ion intercalation / deintercalation also appeared in the potential range from $0.2 \mathrm{~V}$ to $0 \mathrm{~V}$. The results suggested that the irreversible reduction current of the NG-3 electrode in the melt was repressed using PAA as the binder.

Fig. 2 shows the charge-discharge curves of the NG-3 electrodes at a constant current density of $175 \mathrm{~mA} \mathrm{~g}^{-1}(0.5 C)$. In this paper, the cathodic polarization due to the $\mathrm{Li}(\mathrm{I})$ ion intercalation into the graphite layer is defined as a charge and the anodic polarization due to the $\mathrm{Li}(\mathrm{I})$ ion deintercalation is defined as a discharge. The charge-discharge curves of the NG-3 electrode using PVdF as the binder are shown in Fig. 2(a). The discharge capacity and the charge-discharge efficiency at the 1 st cycle were $166.5 \mathrm{mAh} \mathrm{g}^{-1}$ and $31.7 \%$, respectively. The discharge capacity and the charge-discharge efficiency at the 2nd cycle were $290.9 \mathrm{mAh} \mathrm{g}^{-1}$ and $60.4 \%$, respectively. The potential plateaus appeared at almost the same potential as the reduction wave of ca. $2.8 \mathrm{~V}$ observed in the $\mathrm{CV}$ (Fig. 1(a)) during the 1st charge, which might be due to the reduction of $\mathrm{SOCl}_{2}[16]$. In addition, the initial charge-discharge profile of the NG-3 electrode using PVdF as a binder was very similar to that of the binder-free natural graphite electrode, and the charge-discharge efficiency of the binder-free natural graphite at the 1 st cycle (37.3\%) was close to that of the electrode using the PVdF binder (31.7 \%) [14], indicating that the presence of the PVdF binder has little influence on the electrochemical characteristics of the natural graphite electrode. In contrast, 
the charge-discharge curves of the NG-3 electrode coated with PAA as a binder are shown in Fig. 2(b). The discharge capacity and the charge-discharge efficiency at the 1st cycle were $322.8 \mathrm{mAh} \mathrm{g}^{-1}$ and $65.6 \%$, respectively. The discharge capacity and the charge-discharge efficiency at the 2 nd cycle were $322.7 \mathrm{mAh} \mathrm{g}^{-1}$ and $78.3 \%$, respectively. After initial 2 cyclings, the charge-discharge curves were stabilized. Especially, the potential plateaus between $1.0 \mathrm{~V}$ and $3.0 \mathrm{~V}$, which were observed in the case of the NG-3 electrode using the PVdF binder, were not observed as suggested from the CV (Fig. 1(b)). Based on these results, the first point to note is that the PAA binder can effectively improve the initial electrochemical characteristics of the NG-3 electrode.

Fig. 3 indicates the cycle performance of the NG-3 electrodes. The cycle performance and the charge-discharge efficiency of the NG-3 electrode using PVdF as a binder are shown in Fig. 3(a). Although the reversible discharge capacity was maintained at ca. 300 $\mathrm{mAh} \mathrm{g}^{-1}$ from the 2 nd cycle to the 10 th cycle, it rapidly faded after the 11 th cycle. The discharge capacity at the 50th cycle decreased to $91.6 \mathrm{mAh} \mathrm{g}^{-1}$. In contrast, the cycle performance and the charge-discharge efficiency of the NG-3 electrode coated with PAA as a binder are shown in Fig. 3(b). During 50 cyclings, the reversible discharge capacity was rather constant and the charge-discharge efficiency was maintained at around $80 \%$. The discharge capacity and the charge-discharge efficiency at the 50th cycle were $302.1 \mathrm{mAh}$ $\mathrm{g}^{-1}$ and $83.9 \%$, respectively. Based on these results, more noteworthy is that the NG-3 electrode coated with the PAA binder showed a better cycle performance. It is considered that the significant capacity fade in the NG-3 electrode using the PVdF binder would be caused by the electrochemical local isolation of the particles as will be described later.

The surface of the NG-3 electrode before and after charging was observed (Fig. 4). Fig. 
4(a) is a close-up photograph of the NG-3 electrode coated with the PAA binder before charging. As seen in the photo, the surface of the graphite electrode was black. The surface of the NG-3 electrode using the PVdF binder was the same as that coated with the PAA binder. Fig. 4(b) is a photograph of the NG-3 electrode using the PVdF binder after charging down to $5 \mathrm{mV}$. As seen in the photo(b), the surface of the graphite electrode changed to gray, indicating that the 1 st stage $\mathrm{LiC}_{6}$ would not be formed by the $\mathrm{Li}(\mathrm{I})$ ion intercalation into graphite layers during charging. In contrast, Fig. 4(c) is a photograph of the NG-3 electrode coated with the PAA binder after charging down to $5 \mathrm{mV}$. As seen in the photo(c), the surface of the graphite electrode after charging changed to a golden-yellow color. This indicates that the 1 st stage $\mathrm{LiC}_{6}$ would be formed during charging [17]. However, the both surfaces of the NG-3 electrodes ( $b$ and c) became black after discharging up to $2.0 \mathrm{~V}$, suggesting that the electrochemical intercalation of the $\mathrm{Li}(\mathrm{I})$ ion in the NG-3 electrode occurred in a reversible manner in the melt.

The ex situ XRD patterns were measured in order to investigate the structural change in the NG-3 electrode during the 1st charge-discharge. Fig. 5(a) indicates the ex situ XRD patterns of the NG-3 electrode using the PVdF binder. The (002) and (004) peaks observed at $26.4^{\circ}(d=338 \mathrm{pm})$ and $54.6^{\circ}(d=168 \mathrm{pm})$, respectively, were ascribed to the diffraction peaks of the natural graphite before charging. The diffraction peaks of the natural graphite shifted to the lower positions of $24.1^{\circ}(d=370 \mathrm{pm})$ and $49.3^{\circ}(d=185 \mathrm{pm})$ corresponding to (001) and (002), respectively, after charging down to $5 \mathrm{mV}$. This indicates that the distance between the graphite layers increased due to the $\operatorname{Li}(\mathrm{I})$ ion intercalation after charging. These values correspond to the formation of the stage 1 intercalation compound, 
$\mathrm{LiC}_{6}$. However, as has been pointed out in Fig. 4, the amount of the $\mathrm{LiC}_{6}$ formed would be very small. After charging down to $5 \mathrm{mV}$, the peaks of $\mathrm{LiC}_{6}$ were detected as only small peak, indicating that a small amount of $\mathrm{LiC}_{6}$ phase would be formed after charging. This XRD pattern corresponds to the close-up photograph of Fig. 4(b). It seems reasonable to suggest that the $\operatorname{Li}(\mathrm{I})$ ion intercalation into the graphite layers could not totally occur because the strain of the graphite layer would be increased and then the particles would become electrochemically isolated by the local exfoliation of graphite layer due to the formation of $\mathrm{LiC}_{12}$ [18]. In the case of the PAA binder, the stack of the electrochemical local isolation may be repressed physically and mechanically because the graphite particles would coat with it more completely. Therefore, the surface of the NG-3 electrode using the PVdF binder after charging did not change to a golden-yellow color, as shown in Fig. 4(b). After discharging, however, the peaks of $\mathrm{LiC}_{12}$ disappeared and the structure of graphite was almost recovered. In contrast, the ex situ XRD patterns of the NG-3 electrode coated with the PAA binder are shown in Fig. 5(b). The peaks of $\mathrm{LiC}_{12}$ and $\mathrm{LiC}_{6}$ appeared similar to those of the NG-3 electrode using the PVdF binder after charging. The peak intensity of $\mathrm{LiC}_{6}$ is higher in comparison to that of the NG-3 electrode using the PVdF binder, and the formation of the $\mathrm{LiC}_{6}$ phase was obviously observed at $2 \theta=24.1^{\circ}$ and $49.3^{\circ}$. This may be due to the reinforcement with an extra connection by the esterification between hydroxyls on edge of the graphite and the carboxyls in the PAA [19]. As a result, it is suggested that the irreversible reduction of $\mathrm{SOCl}_{2}$ would be repressed because PAA acted as an organic layer for the quasi-SEI film effectively. Based on the results, it was found that PAA was more effective as a binder. 
Moreover, it is interesting to note that the peaks of $\mathrm{LiCl}$ were obviously observed on the graphite surface after charging regardless of the binder types (Figs. 5(a II ) and (b II )). As $\mathrm{LiCl}$ was more clearly detected after discharging, it is found that it remained on the graphite surface (Figs. 5(aIII) and (b III)). As shown in Figs. 5(a I ) and (b I ), LiCl was not formed on the graphite surface during immersing the graphite electrodes in the melt or before charging. Furthermore, the XPS measurements showed that $\mathrm{Cl}^{-}$ions were included in the surface film on the graphite electrodes after charging and discharging (Fig. 6). The two XPS peaks can be ascribed to the formation of $\mathrm{LiCl}$, because these binding energies almost correspond to the literature values $\left(\mathrm{Cl}_{2 \mathrm{p} 1 / 2}(199.5 \mathrm{eV})\right.$ and $\left.\mathrm{Cl}_{2 \mathrm{p} 3 / 2}(197.5 \mathrm{eV})\right)[20,21]$. The main ionic species in the melt were thought to be $\mathrm{EMI}^{+}, \mathrm{Li}(\mathrm{I})$, and $\mathrm{AlCl}_{4}{ }^{-}$[11]. Thus, it is assumed that the $\mathrm{AlCl}_{4}{ }^{-}$ion is reduced electrochemically, resulting in the formation of $\mathrm{LiCl}$ at $-1.4 \mathrm{~V}$ vs. $\mathrm{Al} / \mathrm{Al}(\mathrm{III})(=0.8 \mathrm{~V}$ vs. $\mathrm{Li} / \mathrm{Li}(\mathrm{I}),[15])$ according to Eq. (1) [2].

$$
\mathrm{AlCl}_{4}^{-}+4 \mathrm{Li}(\mathrm{I})+3 \mathrm{e}^{-} \rightarrow \mathrm{Al}(\mathrm{s})+4 \mathrm{LiCl}(\mathrm{s})
$$

In the case of several RTILs, several researches on the electrochemical reduction of the $\mathrm{AlCl}_{4}{ }_{4}^{-}$and $\left(\mathrm{CF}_{3} \mathrm{SO}_{2}\right)_{2} \mathrm{~N}^{-}$have been reported $[2,22]$. Based on the results, it was considered that the PAA binder would not repress the reduction reaction of $\mathrm{AlCl}_{4}{ }^{-}$at $0 \sim 1.0 \mathrm{~V}$ although it would effectively repress the reduction reaction of $\mathrm{SOCl}_{2}$ at $1.2 \sim 3.2 \mathrm{~V}$.

\section{Conclusions}

We tried to improve the electrochemical characteristics of the natural graphite negative 
electrode in the $66.7 \mathrm{~mol} \% \mathrm{AlCl}_{3}-33.3 \mathrm{~mol} \% \mathrm{EMIC}^{-\mathrm{LiCl}_{\text {sat. }}}+0.1 \mathrm{~mol} \mathrm{dm} \mathrm{SOCl}_{2} \mathrm{melt}^{-3}$ The use of the PAA binder enabled to improve its capacity retention and the initial cycling efficiency of the NG-3 electrode. Especially, the intercalation and deintercalation reactions of the $\mathrm{Li}(\mathrm{I})$ ion into and from the graphite layer were enhanced in a reversible manner because the reduction reaction derived from $\mathrm{SOCl}_{2}$ would be repressed. It was suggested that the main side reaction of Eq. (1) during charging would be the formation of $\mathrm{LiCl}$ on the graphite surface regardless of the binder types.

This study is the first report concerning the characterization of the deposit, like the inorganic components in the SEI film, on the natural graphite electrode in the RTILs electrolyte.

\section{Acknowledgements}

This work was partially supported by a Grant-in-Aid for Scientific Research from the Japanese Ministry of Education, Science, Sports and Culture (no. 17073013).

\section{References}

1) R. T. Carlin, H. C. De Long, J. Fuller, and P. C. Trulove, J. Electrochem. Soc., 141, (1994) L73.

2) R. T. Carlin, J. Fuller, W. K. Kuhn, M. J. Lysaght, and P. C. Trulove, J. Appl. Electrochem., 26, (1996) 1147.

3) H. Zheng, K. Jiang, T. Abe, and Z. Ogumi, Carbon, 44, (2006) 203.

4) S. Seki, Y. Kobayashi, H. Miyashiro, Y. Ohno, Y. Mita, A. Usami, N. Terada, and M. 
Watanabe, Electrochem. Solid-State Lett., 8, (2005) A577.

5) M. Ishikawa, T. Sugimoto, M. Kikuta, E. Ishiko, and M. Kono, J. Power Sources., 162, (2006) 658.

6) S. Seki, Y. Kobayashi, H. Miyashiro, Y. Ohno, Y. Mita, N. Terada, P. Charest, A. Guerfi, and K. Zaghib, J. Phys. Chem. C, 112, (2008) 16708.

7) K. Ui, S. Kikuchi, F. Mikami, Y. Kadoma, and N. Kumagai, J. Power Sources., 173, (2007) 518 .

8) A. N. Dey and B. P. Sullivan, J. Electrochem. Soc., 117, (1970) 222.

9) N. Koura and K. Ui, J. Jpn. Inst. Light Met., 47, (1997) 267.

10) K. Ui, N. Koura, Y. Idemoto, and K. Iizuka, Denki Kagaku, 65, (1997) 161 (presently Electrochemistry).

11) N. Koura, K. Iizuka, Y. Idemoto, and K. Ui, Electrochemistry, 67, (1999) 706.

12) K. Ui, K. Yamamoto, K. Ishikawa, T. Minami, K. Takeuchi, M. Itagaki, K. Watanabe, and N. Koura, J. Power Sources., 183, (2008) 347.

13) N. Koura, K. Etoh, Y. Idemoto, and F. Matsumoto, Chem. Lett., (2001) 1320.

14) K. Ui, T. Minami, K. Ishikawa, Y. Idemoto, and N. Koura, J. Power Sources., 146, (2005) 698.

15) K. Ui, K. Ishikawa, T. Furuya, Y. Idemoto, and N. Koura, Electrochemistry, 73, (2005) 120.

16) J. Fuller and R. A. Osteryoung, J. Electrochem. Soc., 142, (1995) 3632.

17) M. Letellier, F. Chevallier, and M. Morerette, Carbon, 45, (2007) 1025.

18) J. Drofenik, M. Gaberscek, R. Dominko, F. W. Poulsen, M. Mongensen, S. Pejovnik, J. Jamnik, Electrochim. Acta, 48, (2003) 883. 
19) N. Ding, J. Xu, Y. Yao, G. Wegner, I. Lieberwirth, and C. Chen, J. Power Sources., 192, (2009) 644.

20) J. F. Moulder, W. F. Stickle, P. E. Sobol and K. D. Bomben, Handbook of X-ray Photoelectron Spectroscopy, Physical Electronics, Inc., US, 1995, (1995) p. 62-63.

21) J. Arai, H. Katayama, and H. Akahoshi, J. Electrochem. Soc., 149, (2002) A217.

22) P. C. Howlett, N. Brack, A. F. Hollenkamp, M. Forsyth, and D. R. MacFarlane, J. Electrochem. Soc., 153, (2006) A595. 


\section{All figure captions}

Fig. 1. Cyclic voltammograms of NG-3 electrodes coated with PVdF and PAA as a binder in the $66.7 \mathrm{~mol} \% \mathrm{AlCl}_{3}-33.3 \mathrm{~mol} \% \mathrm{EMIC}_{-\mathrm{LiCl}_{\text {sat. }}}+0.1 \mathrm{~mol} \mathrm{dm}^{-3} \mathrm{SOCl}_{2}$ electrolyte. Scan rate: $0.1 \mathrm{mV} \mathrm{s}^{-1}$; (a) PVdF $10 \mathrm{wt} . \%$ and (b) PAA $10 \mathrm{wt} . \%$.

Fig. 2. Charge - discharge curves of NG-3 electrodes coated with PVdF and PAA as the

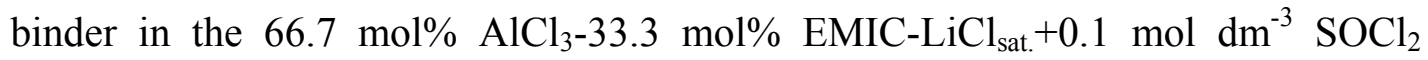
electrolyte; C.D., $175 \mathrm{~mA} \mathrm{~g}^{-1}$ (0.5C); (a) PVdF 10 wt.\% and (b) PAA 10 wt.\%.

Fig. 3. Cycle performonce of NG-3 electrodes coated with PVdF and PAA as the binder in the $66.7 \mathrm{~mol}^{\%} \mathrm{AlCl}_{3}-33.3 \mathrm{~mol} \% \mathrm{EMIC}-\mathrm{LiCl}_{\text {sat. }}+0.1 \mathrm{~mol} \mathrm{dm} \mathrm{SOCl}_{2}$ electrolyte; potential range: $5 \mathrm{mV} \sim 2.0 \mathrm{~V}$ vs. $\mathrm{Li} / \mathrm{Li}(\mathrm{I})$, C.D., $175 \mathrm{~mA} \mathrm{~g}^{-1}$ (0.5C); (a) PVdF 10 wt.\% and (b) PAA 10 wt.\% ; $(\bigcirc)$ discharge capacity; ( $)$ charge-discharge efficiency.

Fig. 4. Photograph of NG-3 electrodes coated with PVdF and PAA as the binder before and after charging down to $5 \mathrm{mV}$ vs. $\mathrm{Li} / \mathrm{Li}(\mathrm{I})$ in the $66.7 \mathrm{~mol} \% \mathrm{AlCl}_{3}-33.3 \mathrm{~mol} \%$ EMIC-LiCl $1_{\text {sat. }}+0.1 \mathrm{~mol} \mathrm{dm}^{-3} \mathrm{SOCl}_{2}$ electrolyte; (a) PAA $10 \mathrm{wt} . \%$ before charging (b) PVdF 10 wt.\% after charging and (c) PAA 10 wt.\% after charging.

Fig. 5. Ex situ XRD patterns of NG-3 electrodes coated with PVdF and PAA as the binder in the $66.7 \mathrm{~mol} \% \mathrm{AlCl}_{3}-33.3 \mathrm{~mol} \% \mathrm{EMIC} \mathrm{LiCl}_{\mathrm{sat} .}+0.1 \mathrm{~mol} \mathrm{dm}^{-3} \mathrm{SOCl}_{2}$ electrolyte;

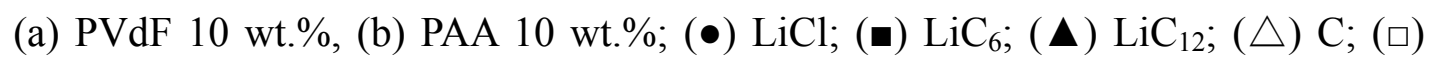
$\mathrm{Ni}(\mathrm{sub}$.$) ; (०) polypropylene film. In both cases, X-ray diffractions were taken ( I )$ before charging ( II ), after charging down to $5 \mathrm{mV}$ vs. $\mathrm{Li} / \mathrm{Li}(\mathrm{I}$ ), and (III) 
discharging up to $2.0 \mathrm{~V}$ vs. $\mathrm{Li} / \mathrm{Li}(\mathrm{I})$.

Fig. 6. High resolution XPS spectra of $\mathrm{Cl}_{2 \mathrm{p}}$ region for $\mathrm{NG}-3$ electrodes coated with $\mathrm{PVdF}$ and PAA as the binder in the $66.7 \mathrm{~mol} \% \mathrm{AlCl}_{3}-33.3 \mathrm{~mol} \% \mathrm{EMIC}_{\mathrm{LiCl}} \mathrm{sat}_{\text {. }}+0.1 \mathrm{~mol}$ $\mathrm{dm}^{-3} \mathrm{SOCl}_{2}$ electrolyte; (a) PVdF 10 wt.\% after charging down to $5 \mathrm{mV}$ vs. Li/ Li( I ), (b) PVdF 10 wt.\% discharging up to 2.0 V vs. Li/ Li( I ). (c) PAA 10 wt.\% after charging down to $5 \mathrm{mV}$ vs. Li/ Li( I ), (d) PAA 10 wt.\% discharging up to 2.0 V vs. Li/ Li( I ). 


\section{Figures:}

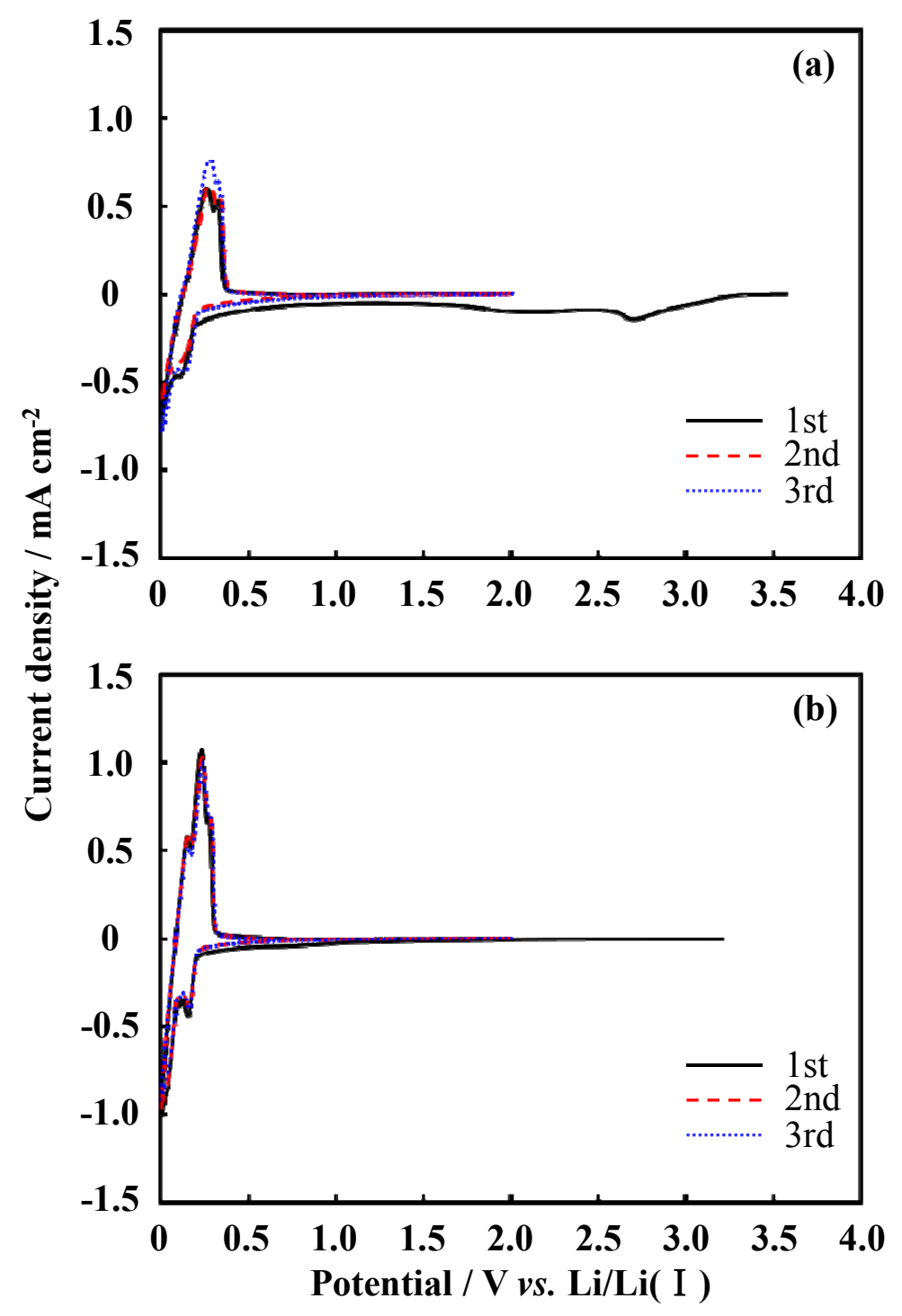

Fig. 1. 


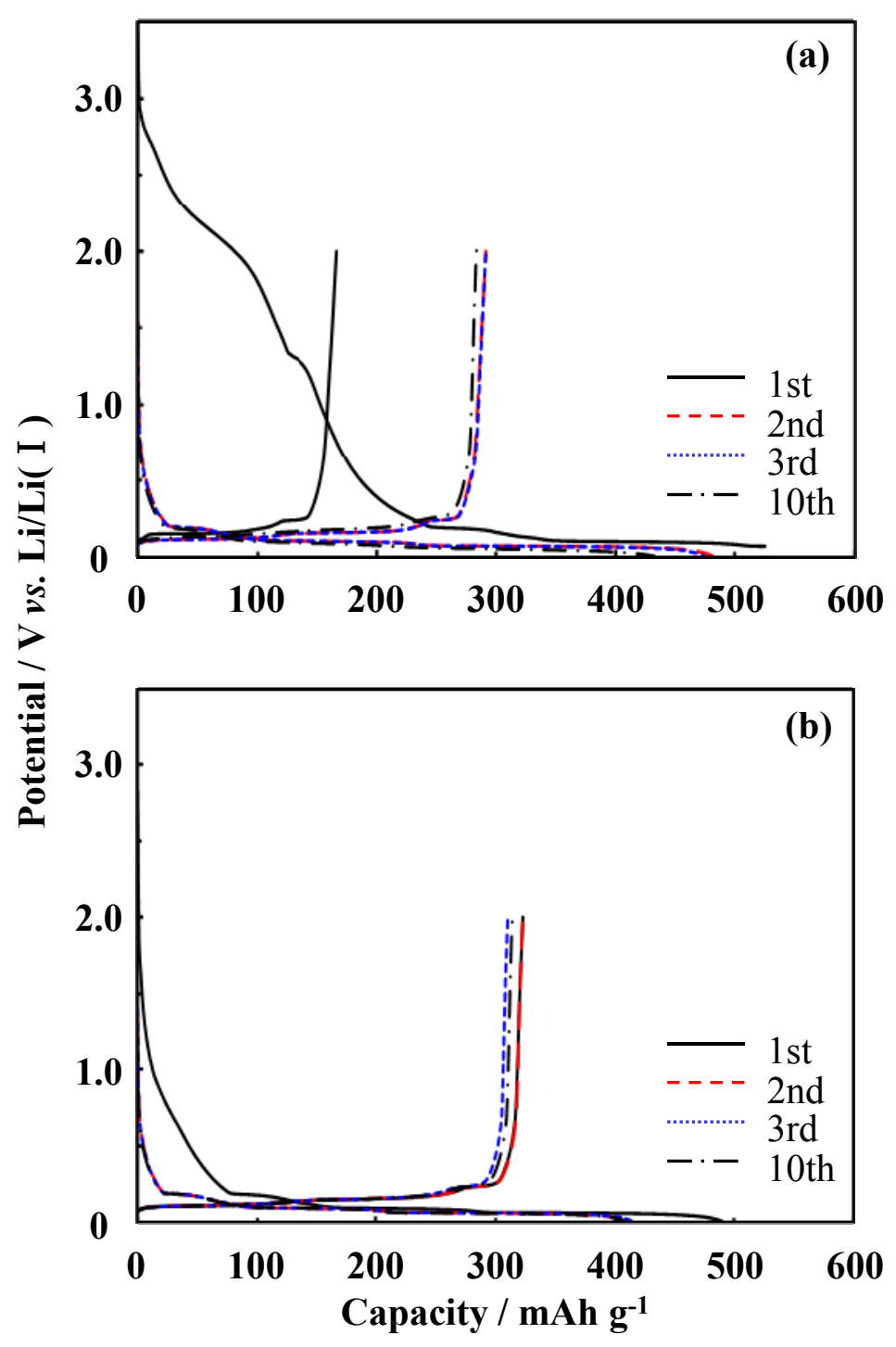

Fig. 2. 


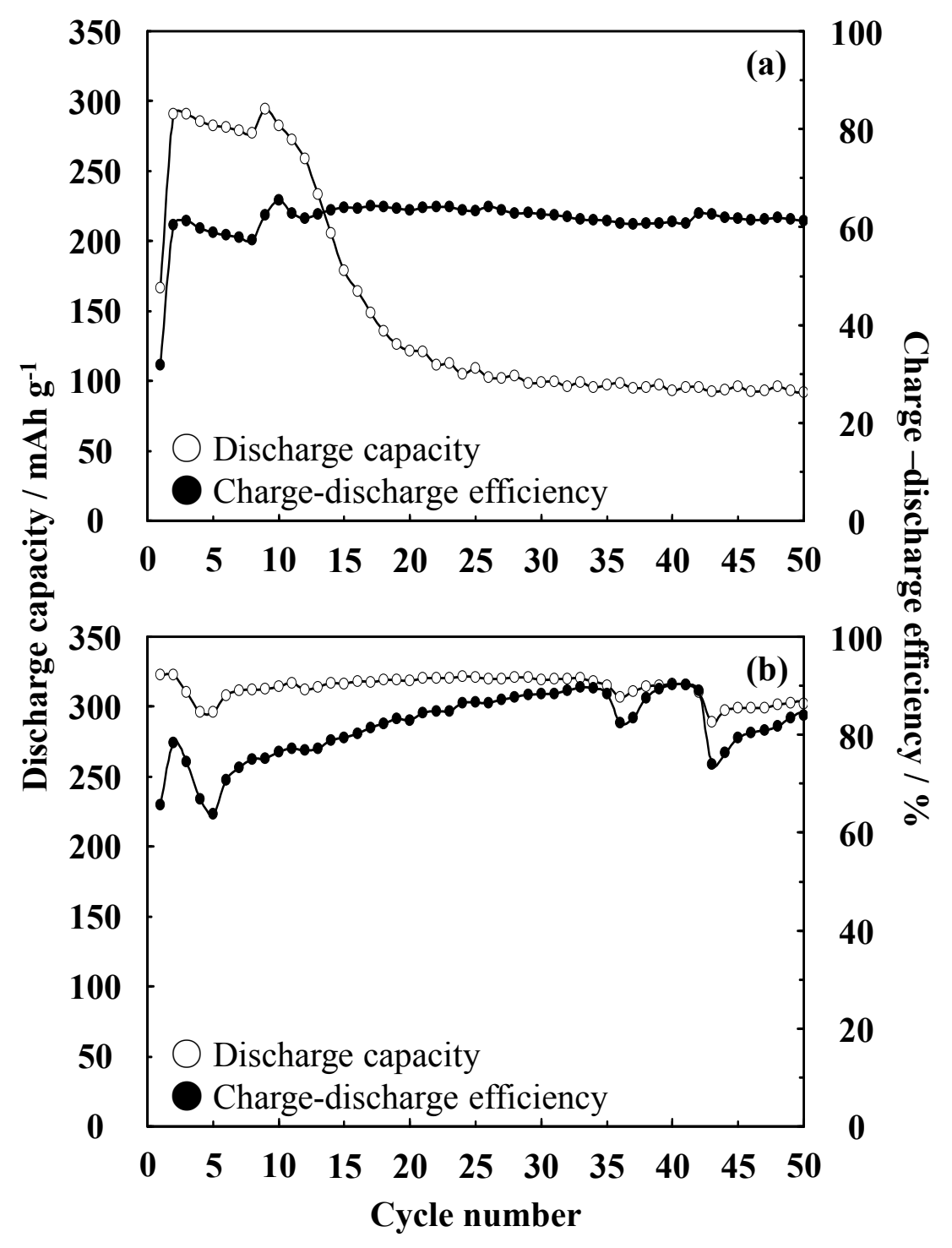

Fig. 3. 


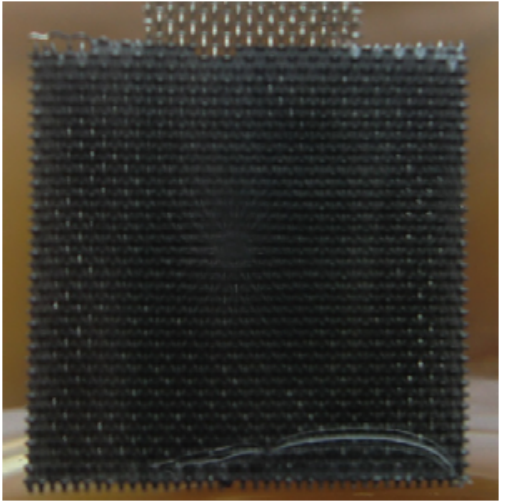

(a)

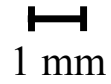

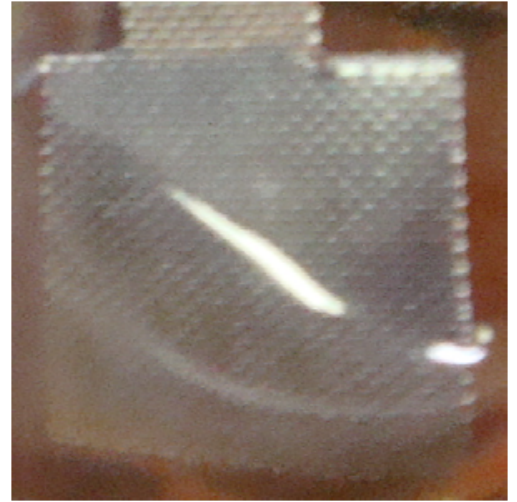

(b)

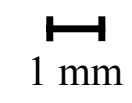

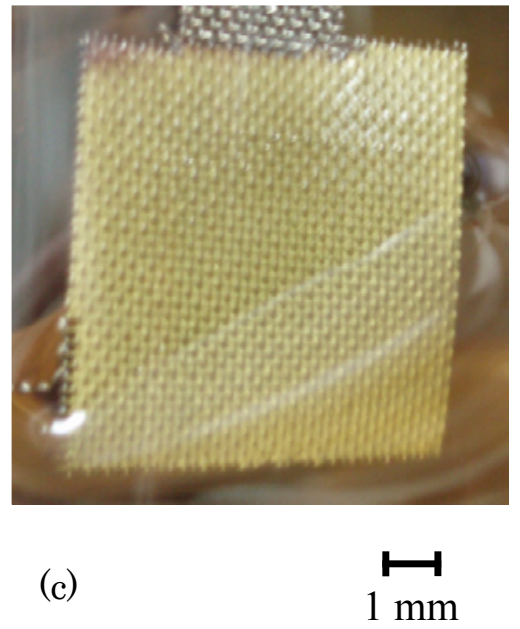

$1 \mathrm{~mm}$

Fig. 4. 


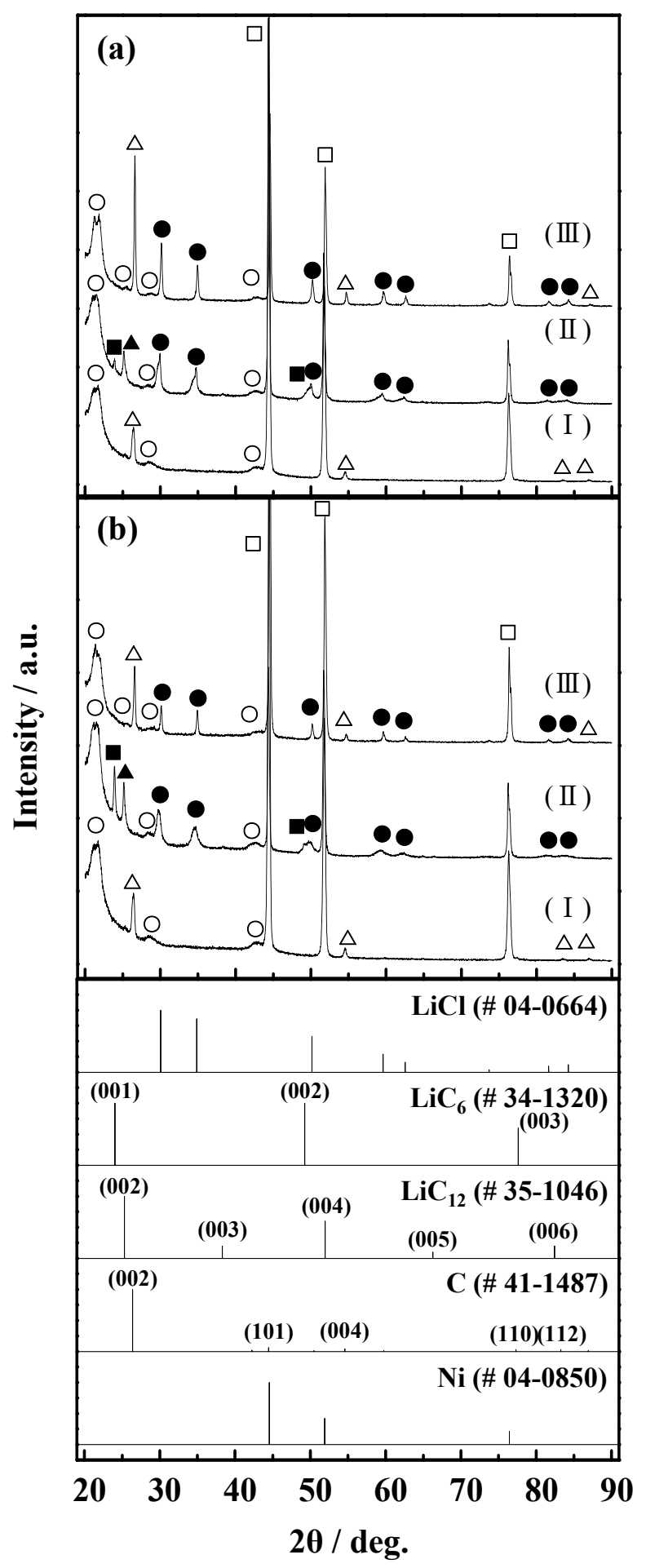

Fig. 5. 


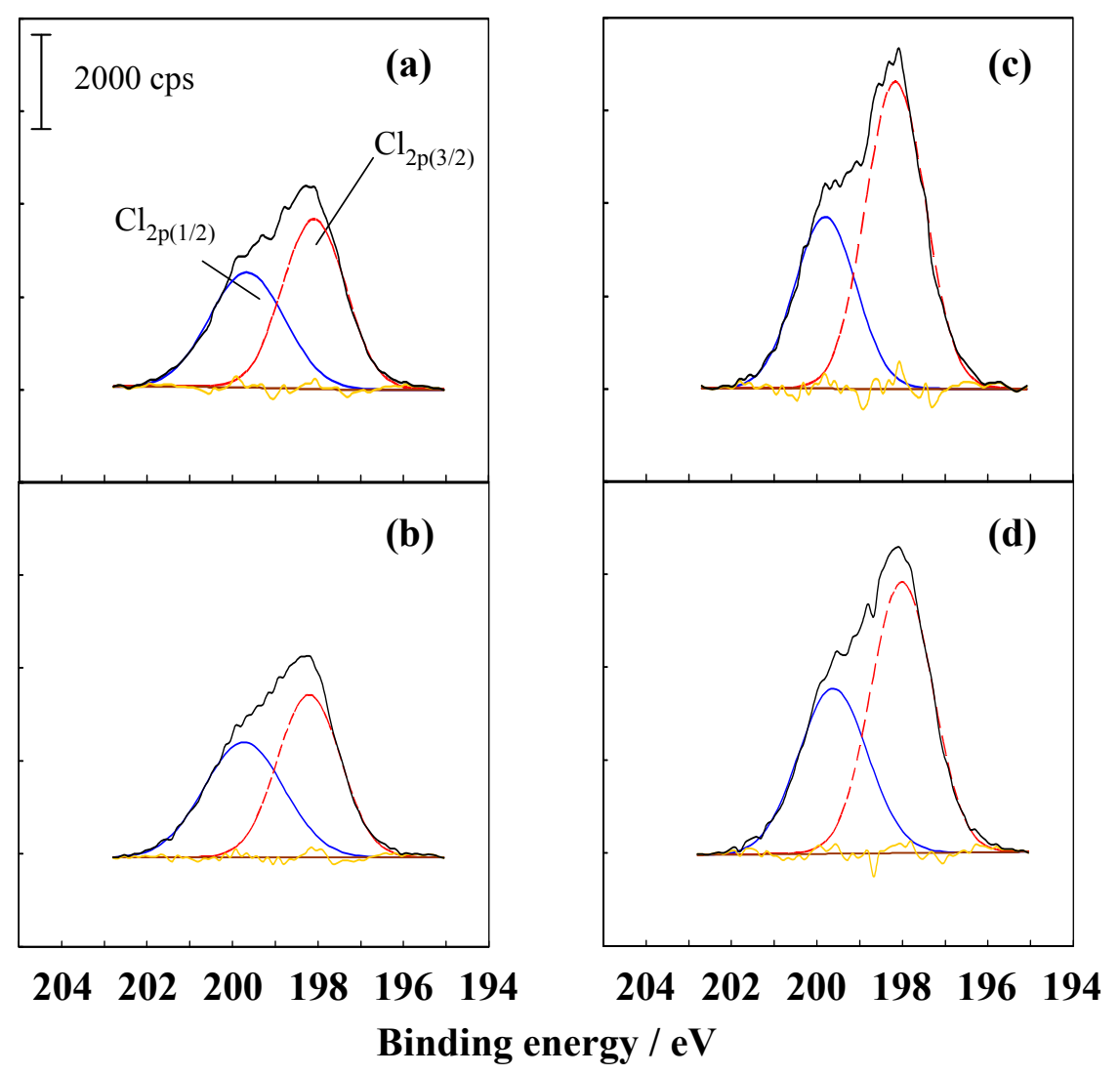

Fig. 6. 